\title{
Seletividade e eficácia de herbicidas para cultura do feijão-caupi ${ }^{1}$
}

\author{
Herbicide selectivity and efficacy to cowpea
}

\author{
José Roberto Antoniol Fontes ${ }^{2}$; Inocencio Junior Oliveira ${ }^{3}$; José Ricardo Pupo Gonçalves ${ }^{4}$
}

Resumo - O feijão-caupi é cultivado principalmente por agricultores familiares, com adoção de baixo nível tecnológico, onde o manejo de plantas daninhas é realizado com capinas, sendo cansativa e com baixo rendimento operacional. O objetivo deste trabalho foi avaliar a seletividade de herbicidas e a eficácia de controle de plantas daninhas na cultura do feijão-caupi, variedade BRS Guariba. O experimento foi conduzido à campo com aplicação dos herbicidas ( $\mathrm{g}$ i.a. ha $^{-1}$ ) sulfentrazone (500) e oxadiazon (600), em pré-emergência, e bentazon (600), bentazon + paraquat $(39+62)$, fomesafen (225), fluazifop-p-butyl (250) e fomesafen + fluazifop-p-butyl $(125+125)$, em pós-emegência, um tratamento com capina aos 20 e 35 dias após a emergência da cultura, e uma testemunha sem capina durante todo o ciclo da cultura. A aplicação do bentazon + paraquat provocou elevada fitotoxicidade no feijão-caupi, e o oxadiazon, sulfentrazone, bentazon e fluazifop-p-butyl garantiram de bom a excelente o controle das plantas daninhas, com produtividades semelhantes à obtida quando o controle foi realizado com duas capinas. $\mathrm{O}$ fomesafen associado ou não ao fluazifop-p-butyl provocou fitointoxicação moderada, atrasos no florescimento e colheita e redução de produtividade da cultura. A interferência de plantas daninhas durante todo o ciclo da cultura reduziu a produtividade de grãos em $42 \%$.

Palavras-chaves: Vigna unguiculata, planta daninha, controle químico, fitotoxicidade

Abstract - Cowpea is grown mainly by smallholders using low technological level, where weeds management is conducted by hoeing, a tiresome and low efficiency action. The aim of this study was to evaluate herbicide selectivity and weed control efficacy in cowpea, BRS Guariba cultivar. The experiment was conducted out with the application of herbicides $\left(\mathrm{g}\right.$ a.e. $\left.\mathrm{ha}^{-1}\right)$ sulfentrazone (500) e oxadiazon (600), in pre emergence conditions, and bentazon (600), bentazon + paraquat $(39+62)$, fomesafen (225), fluazifop-p-butyl (250) and fomesafen + fluazifop-p-butyl $(125+125)$, in post emergence, one treatment with hoeing at 20 and 34 days after crop emergence and a check with weed interference during the whole crop cycle. Bentazon + paraquat application promoted high phytotoxicity in cowpea, and oxadiazon, sulfentrazone, bentazon and fluazifop-p-butyl guaranteed an excellent control of weeds, with yields similar to those obtained with two hoeing. Fomesafen associated or not to fluazifop-p-butyl caused moderate phytotoxicity, delays flowering and harvest, besides crop yield reduction. Weeds interference during the whole crop cycle reduced grain yield in $42 \%$.

Keywords: Vigna unguiculata, weeds, chemical control, phytotoxicity

\footnotetext{
${ }^{1}$ Recebido para publicação em 25/02/2013 e aceito em 27/04/2013.

${ }^{2}$ Engenheiro Agrônomo, pesquisador da Embrapa Amazônia Ocidental, Rodovia AM 010, km 29, caixa postal 319 , CEP 69010-970, Manaus-AM. jose.roberto@embrapa.br

${ }^{3}$ Engenheiro Agrônomo, pesquisador da Embrapa Amazônia Ocidental, Rodovia AM 010, km 29, caixa postal 319, CEP 69010-970, Manaus-AM. inocencio.oliveira@embrapa.br

${ }^{4}$ Engenheiro Agrônomo, pesquisador da Embrapa Meio Ambiente, Rodovia SP 340, km 127,5, caixa postal 69, CEP 13820-000, Jaguariúna-SP. ricardo.pupo@embrapa.br
} 


\section{Introdução}

O feijão-caupi (Vigna unguiculata) é uma das principais culturas alimentares exploradas no Nordeste e Norte do Brasil, a qual apresenta expansão acentuada para a região Centro-Oeste, como cultura de sucessão ao milho ou a soja (Zilli et al., 2011). A produtividade nas regiões tradicionais é de cerca de $300 \mathrm{~kg} \mathrm{ha}^{-1}$ (Freitas et al. 2009), não muito diferente daquela obtida no continente africano, considerado o maior produtor, em que a produtividade média é de $380 \mathrm{~kg} \mathrm{ha}^{-1}$ (Ishaya et al., 2008). Segundo Silva et al. (2000) e Ishaya et al. (2008), dentre os fatores que interferem negativamente na cultura, encontrase o manejo inadequado das plantas daninhas que contribui para a redução de produtividade. Além disso, algumas espécies de plantas daninhas servem como hospedeiros alternativos de doenças que atacam o feijãocaupi, como são os casos da guanxuma (Sida rhombifolia), malva-sedosa (Waltheria indica), mussambê (Cleome affinis) e mela-bode (Herissantia crispa) (Assunção et al., 2006).

O controle de plantas daninhas no feijão-caupi é realizado por meio de ação mecânica, sobretudo capinas com enxada. Essa característica do sistema de produção do feijãocaupi deve-se ao fato da inexistência de herbicidas registrados, o que impede recomendações de controle químico de plantas daninhas (Freitas et al., 2009). Embora haja tal impedimento, o uso de herbicidas no programas de manejo integrado de plantas daninhas é uma opção promissora, uma vez que melhora a eficácia de controle com redução de custos de produção (Machado et al., 2006). Ademais, o conhecimento sobre a tolerância das variedades de feijão-caupi aos herbicidas ainda é pequeno, devido o número reduzido de pesquisas conduzidas com este objetivo (Harrison \& Fery, 1993).
Portanto, considerando que a tolerância das variedades de feijão-caupi a herbicidas ainda é pouco conhecida, objetivou-se neste trabalho caracterizar a seletividade de herbicidas ao feijão-caupi, variedade BRS Guariba, assim como estimar a eficácia de controle de plantas daninhas proporcionada pelas suas aplicações.

\section{Material e Métodos}

Um experimento de campo foi conduzido entre abril e julho de 2009 com a variedade de feijão-caupi (Vigna unguiculata) BRS Guariba em um LATOSSOLO AMARELO (Embrapa, 2013), cujas características químicas e físicas foram: $\mathrm{pH}$ em água 5,11; matéria orgânica, 41,1 $\mathrm{g} \mathrm{kg}^{-1}$; fósforo, $2 \mathrm{mg} \mathrm{dm}^{-3}$; potássio, $51 \mathrm{mg} \mathrm{dm}^{-3}$; $\mathrm{H}+\mathrm{Al}, 3,94 \mathrm{cmol}_{\mathrm{c}} \mathrm{dm}^{-3}$; soma de bases, 2,49 $\mathrm{cmol}_{\mathrm{c}} \mathrm{dm}^{-3}$, saturação por bases, $38,75 \%$; e saturação por alumínio, 4,22\%, de textura muito argilosa. Na Figura 1 estão apresentadas médias de chuvas e de temperatura do ar no ano de 2009.

Em 23/04, antes do preparo do solo para a semeadura, realizou-se levantamento florístico para caracterizar a comunidade daninha do local do experimento, adotando-se para isso o método do quadrado inventário (Braun-Blanquet, 1979), que consistiu no lançamento aleatório de uma armação quadrada vazada de madeira com $50 \mathrm{~cm}$ de lado, totalizando 25 lançamentos. A cada lançamento, os indivíduos contidos pela armação foram identificados e quantificados por espécie para estimativa de parâmetros populacionais (Mueller-Dombois \& Ellemberg, 1974). A relação de espécies daninhas identificadas na área experimental por ocasião do preparo de solo está apresentada na Tabela 1. 


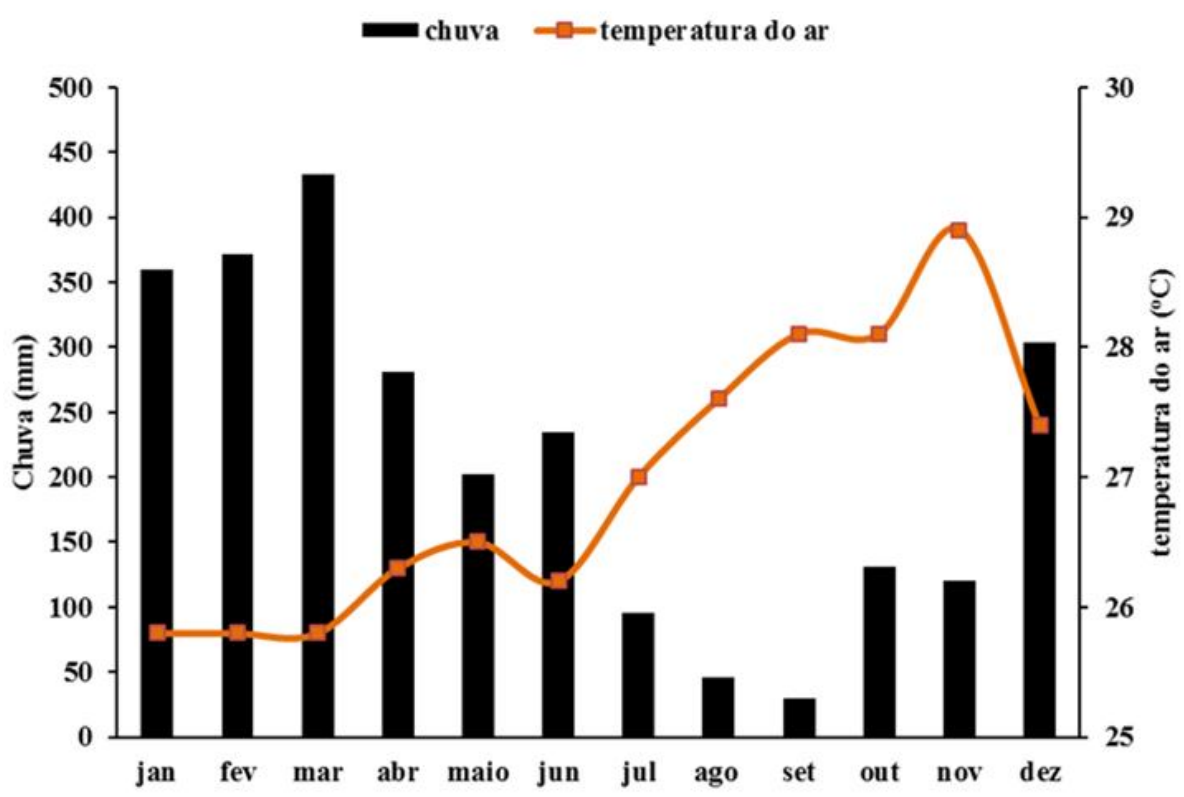

Figura 1. Distribuição de chuvas $(\mathrm{mm})$ e temperatura média do ar $\left({ }^{\circ} \mathrm{C}\right)$ no ano de condução do experimento.

Tabela 1. Nomes científicos, densidade relativa (DR, \%), frequência relativa (FR, \%), abundância relativa (AR, \%) e índice de importância relativa (IIR, \%) das espécies daninhas identificadas na área experimental. Manaus - AM, 2009.

\begin{tabular}{lcccc}
\hline Espécie daninha & DR $(\%)$ & FR $(\%)$ & AR $(\%)$ & IIR $(\%)$ \\
\hline Croton lobatus & 19,49 & 8,11 & 14,68 & 42,28 \\
Cleome affinis & 15,19 & 5,41 & 17,16 & 37,76 \\
Commelina erecta & 9,24 & 5,86 & 9,64 & 24,74 \\
Paspalum virgatum & 7,04 & 7,21 & 5,97 & 20,22 \\
Euphorbia heterophylla & 6,50 & 6,76 & 5,87 & 19,13 \\
Digitaria ciliaris & 4,85 & 5,86 & 5,06 & 15,76 \\
Stachytarpheta cayennensis & 3,93 & 7,66 & 3,14 & 14,73 \\
Spermacoce verticillata & 2,84 & 5,41 & 3,21 & 11,45 \\
Pueraria phaseoloides & 1,92 & 6,31 & 1,86 & 10,09 \\
Mimosa pudica & 2,29 & 3,60 & 3,88 & 9,77 \\
Croton trinitatis & 2,10 & 4,05 & 3,17 & 9,33 \\
Lantana camara & 1,37 & 3,15 & 2,66 & 7,18 \\
Porophyllum ruderale & 0,46 & 2,25 & 1,24 & 3,95 \\
Amaranthus retroflexus & 0,27 & 0,90 & 1,86 & 3,04 \\
\hline
\end{tabular}

O revolvimento da superfície do solo da área experimental, com emprego de arado de discos e grade niveladora, assim como a abertura de sulcos de semeadura e semeadura foram realizados em 05/05. Na adubação de base foi aplicada a mistura equivalente a 200 $\mathrm{kg} \mathrm{ha}^{-1}$ de 04-14-8 e $25 \mathrm{~kg} \mathrm{ha}^{-1}$ de FTE BR12.
As sementes de feijão-caupi foram distribuídas em excesso ao longo dos sulcos, espaçados um do outro em $60 \mathrm{~cm}$, a aproximadamente quatro $\mathrm{cm}$ de profundidade e cobertas com solo. A emergência ocorreu em 08/05, e aos cinco dias após a emergência (DAE) foi realizado o desbaste de plantas de feijão-caupi, para ajuste 
de população equivalente a 133.000 plantas ha ${ }^{-}$ 1. Aos 25 DAE foi realizada adubação em cobertura com aplicação de $35 \mathrm{~kg} \mathrm{ha}^{-1} \mathrm{de} \mathrm{N}$, na forma de sulfato de amônio.

Os tratamentos foram constituídos pela aplicação dos herbicidas, com doses em $\mathrm{g}$ de i.a. ha ${ }^{-1}$, oxadiazon (600) e sulfentrazone (500), em pré-emergência, um dia após a semeadura (com o solo úmido e sem torrões), e bentazon (600), bentazon + paraquat $(39+62)$, fomesafen (225), fluazifop-p-butyl (250) e fomesafen + fluazifop-p-butyl $(125+125)$, aplicados em pós-emergência, aos 14 DAE, quando as plantas de feijão-caupi estavam entre os estádios $\mathrm{V}_{4}$ e $\mathrm{V}_{5}$ (segunda e a terceira folhas trifoliadas com os bordos separados e o limbo completamente expandido). Os herbicidas foram aplicados com um pulverizador pressurizado com dióxido de carbono, em pressão constante de $3 \mathrm{~kg} \mathrm{~cm}^{-2}$, munido com quatro pontas de pulverização tipo leque TT 110.02, espaçadas a $50 \mathrm{~cm}$ uma da outra, com vazão de $130 \mathrm{~L} \mathrm{ha}^{-1}$. Foram incluídas duas testemunhas, uma com controle de plantas daninhas aos 20 e 35 DAE por meio de capina com enxada, e outra, com interferência de plantas daninhas durante o ciclo da cultura.

O delineamento experimental utilizado foi o inteiramente casualizado, com quatro repetições. As unidades experimentais foram constituídas por seis fileiras com seis metros de comprimento, sendo a área útil formada pelas quatro fileiras centrais, descontando-se um metro em cada extremidade.

Aos 14 e 28 dias após a aplicação dos herbicidas (DAA) foram realizadas avaliações visuais de fitotoxicidade em plantas de feijãocaupi e de controle de plantas daninhas, adotando-se escala percentual, onde zero significa ausência de sintomas, e $100 \%$ a morte das plantas (Frans \& Talbert, 1977). Aos 28 DAA estimou-se visualmente a porcentagem de cobertura da superfície do solo pelas plantas daninhas.
O número de dias para a floração após a semeadura foi estimado por meio de avaliação visual, considerando pelo menos metade das plantas exibindo pelo menos uma flor aberta.

A colheita foi realizada manualmente quando pelo menos $80 \%$ das vagens das parcelas encontravam-se secas, ocasião em que também foi estimada a população final de plantas de feijão-caupi por meio da contagem de plantas na área útil das parcelas.

A massa seca total de plantas daninhas $\mathrm{m}^{-2}$ foi estimada por meio da coleta de plantas em dois locais na área útil de cada unidade experimental, utilizando-se uma armação quadrada vazada de madeira com $50 \mathrm{~cm}$ de lado. A parte aérea coletada das plantas daninhas (corte rente ao solo) foi levada para laboratório, lavadas com água corrente e separadas em duas partes, uma formada por plantas de folhas largas (eudicotiledôneas) e a outra por folhas estreitas (monocotiledôneas). Em seguida foram secas em estufa com circulação forçada de ar a $65^{\circ} \mathrm{C}$, até atingir massa constante. As vagens colhidas foram levadas para laboratório, beneficiadas manualmente, os grãos pesados e a umidade determinada por meio de medidor eletrônico.

Os dados foram submetidos à análise de normalidade dos erros (Lilliefors), de homogeneidade de variância dos erros (Cochran) e de variância. As médias de tratamentos foram comparadas pelo teste de Tukey a 5\% de probabilidade. Para as análises estatísticas foi utilizado o programa SAEG 9.1 (SAEG, 2007).

\section{Resultados e Discussão}

O herbicida sulfentrazone (600 $\mathrm{g} \mathrm{ha}^{-1}$ ) não provocou sintomas visuais de fitointoxicação para variedade BRS Guariba (Tabela 2), resultado semelhante ao obtido por Silva et al (2000) em trabalho conduzido em casa-de-vegetação, utilizando a variedade USA. 
Tabela 2. Fitotoxicidade (\%) e controle de plantas daninhas (\%) aos 14 e 28 dias após a aplicação (DAA) dos herbicidas, dias para floração após a semeadura e população final de plantas (plantas/ha) da variedade de feijão-caupi BRS Guariba. Manaus, 2009.

\begin{tabular}{|c|c|c|c|c|c|c|c|c|c|c|c|c|}
\hline \multirow[t]{2}{*}{ Tratamentos } & \multicolumn{4}{|c|}{$\begin{array}{c}\text { Fitotoxicidade } \\
(\%)\end{array}$} & \multicolumn{4}{|c|}{$\begin{array}{c}\text { Controle } \\
(\%)\end{array}$} & \multirow{2}{*}{\multicolumn{2}{|c|}{$\begin{array}{l}\text { Floração } \\
\text { (dias) }\end{array}$}} & \multirow{2}{*}{\multicolumn{2}{|c|}{$\begin{array}{c}\text { População } \\
\text { final } \\
\left.\text { (plantas ha }^{-1}\right)\end{array}$}} \\
\hline & \multicolumn{2}{|c|}{14 DAA } & \multicolumn{2}{|c|}{$28 \mathrm{DAA}$} & \multicolumn{2}{|c|}{14 DAA } & \multicolumn{2}{|c|}{28 DAA } & & & & \\
\hline Oxadiazon & 8 & $\mathrm{a}$ & 5 & $\mathrm{a}$ & 95 & $\mathrm{a}$ & 91 & $\mathrm{a}$ & 42 & a & 130.998 & $\mathrm{a}$ \\
\hline Sulfentrazone & 1 & a & 1 & a & 93 & a & 92 & a & 41 & a & 131.445 & $\mathrm{a}$ \\
\hline Bentazon & 5 & a & 3 & $\mathrm{a}$ & 80 & $\mathrm{~b}$ & 73 & $\mathrm{~b}$ & 42 & a & 128.179 & $\mathrm{a}$ \\
\hline Bentazon+paraquat & 54 & $\mathrm{c}$ & 65 & $\mathrm{c}$ & 92 & a & 90 & a & 55 & $\mathrm{~b}$ & 32.965 & $\mathrm{~b}$ \\
\hline Fomesafen & 34 & $\mathrm{~b}$ & 40 & b & 90 & a & 90 & $\mathrm{a}$ & 54 & $\mathrm{~b}$ & 129.152 & a \\
\hline Fluazifop-p-butyl & 4 & a & 2 & a & 58 & $\mathrm{c}$ & 50 & $\mathrm{c}$ & 41 & a & 130.000 & $\mathrm{a}$ \\
\hline Fomesafen+fluazifop-p-butyl & 19 & $\mathrm{~b}$ & 31 & b & 95 & a & 90 & a & 53 & a & 127.741 & $\mathrm{a}$ \\
\hline Testemunha capinada & 0 & $\mathrm{a}$ & 0 & a & 95 & $\mathrm{a}$ & 90 & a & 41 & a & 128.935 & $\mathrm{a}$ \\
\hline Testemunha sem capina & 0 & $\mathrm{a}$ & & $\mathrm{a}$ & 0 & $\mathrm{c}$ & 0 & $\mathrm{c}$ & 42 & $\mathrm{a}$ & 128.810 & a \\
\hline Coeficiente de variação (\%) & & 2,0 & & 1,6 & 26 & & & ,4 & & 1,2 & 19,2 & \\
\hline
\end{tabular}

O herbicida oxadiazon provocou leve amarelecimento leve e encarquilhamento apenas nos bordos das folhas cotiledonares, não sendo significativo o nível de dano se comparado com as plantas dos tratamentos sem aplicação de herbicida. Esses sintomas foram semelhantes aos relatados por Fontes et al. (2010), quando utilizado doses de até $1.000 \mathrm{~g}$ i.a. ha ${ }^{-1}$ do oxadiazon. Nenhum dos herbicidas aplicados em pré-emergência afetou a população final de plantas, visto que os resultados obtidos foram significativamente $(p$ $\leq 0,05)$ semelhantes às testemunhas sem aplicação de herbicidas.

A mistura do bentazon + paraquat provocou forte fitointoxicação à cultura e redução da população de plantas da variedade BRS Guariba, significativamente superiores ( $p$ $\leq 0,05)$ aos demais tratamentos. Para o feijãocomum a recomendação é de que a aplicação desta mistura deve ser feita até o estádio de crescimento de segunda folha trifoliolada (Rodrigues \& Almeida, 2011). No trabalho, a aplicação da mistura nas plantas foi realizada entre os estádios $V_{4}$ e $V_{5}$, e considerando que o bentazon aplicado isoladamente foi pouco fitotóxico à variedade BRS Guariba (tabela 2), fica evidente que a ação do paraquat foi a responsável pelos severos danos severos verificados às plantas. Harrison \& Fery (1993) constataram grande variabilidade na tolerância de genótipos de feijão-caupi ao herbicida bentazon. Os genótipos mais suscetíveis foram mortos ou afetados severamente com aplicações de $2 \mathrm{~kg}$ i.a. ha ${ }^{-1}$, enquanto os mais tolerantes resistiram a doses de até $16 \mathrm{~kg}$ i.a. $\mathrm{ha}^{-1}$.

O fomesafen aplicado isoladamente ou em mistura ao fluazifop-p-butyl provocou intoxicação moderada às plantas de feijãocaupi, que foi creditada ao fomesafen, pois a aplicação isolada do fluazifop-p-butyl praticamente não afetou as plantas da cultura. Foram observadas lesões necróticas em todo o limbo foliar, nos pecíolos e nas hastes que receberam a aplicação dos herbicidas, resultando em intensa queda de folhas. $O$ fomesafen tem ação de contato, promovendo a peroxidação de lipídios das membranas celulares e morte das plantas sensíveis (Vidal, 1997), sendo um dos herbicidas mais utilizados para controle de plantas daninhas eudicotiledôneas nas culturas do feijão-comum (Phaseoulus vulgaris) e soja (Glycine max) (Fontes et al., 2006; Machado et al., 2006).

Apesar da intoxicação das plantas de feijão-caupi que receberam a aplicação e fomesafen e fomesafen + fluazifop-p-butyl ter sido significativamente superior $(p \leq 0,05)$ as testemunhas sem aplicação de herbicidas, a população final de plantas não foi significativamente afetada. Comparando ao 
feijoeiro-comum, Machado et al. (2006), verificaram que o fomesafen provocou fitotoxicidade em plantas da variedade Meia Noite, cultivado no sistema plantio direto, em doses superiores a $100 \mathrm{~g}$ i.a. ha ${ }^{-1}$, sem, entretanto, afetar outras características das plantas.

O número de dias entre a semeadura e a floração das plantas da variedade BRS Guariba aumentou significativamente $(p \leq 0,05)$ com a aplicação dos herbicidas bentazon + paraquat, fomesafen e fomesafen + fluazifop-p-butyl. Nessas situações verificou-se alta perda de área foliar por necrose de tecido e queda de folhas das plantas decorrente da ação dos herbicidas que, contudo, não foi suficiente para provocar a morte das mesmas. As plantas afetadas pelo bentazon + paraquat e fomesafen continuaram a emitir brotações a partir das gemas que não foram afetadas pelos herbicidas. Segundo Mondal et al. (2011), as folhas são responsáveis pela maior parte dos assimilados produzidos pelas plantas necessários ao desenvolvimento dos demais órgãos vegetais. Ibrahim et al. (2010) relataram que o desfolhamento do feijão-caupi, variedade IT92KD 267-2, 35 dias após a semeadura (fase vegetativa) resultou em menor número de ramos, de folhas, do número de flores e da altura de plantas, além de aumentar o número de dias para a floração. Mondal et al. (2011) avaliaram a influência da desfolha de plantas de feijão-mungo-verde (Vigna radiata) na formação de flores e de vagens, concluindo que a perda de folhas, sobretudo da parte superior do dossel, foi muito prejudicial à formação de flores e de vagens e, consequentemente, à produção de grãos.

O herbicida fluazifop-p-butyl não afetou nenhuma característica das plantas da variedade BRS Guariba, mostrando elevada seletividade a esta variedade. Em condição de campo, Silva et al. (2003) também constataram que o fenoxaprop-p-ethyl (40, 80 e 120 g i.a. $\mathrm{ha}^{-1}$ ) não causou injúrias às plantas da variedade EPACE-10.

O nível de controle de plantas daninhas obtido com a aplicação em pré-emergência para oxadiazon e sulfentrazone foi excelente, proporcionando as menores coberturas da superfície do solo, com reduções de massas secas totais de plantas daninhas de $93 \%$ e $88 \%$, respectivamente, em relação a testemunha sem controle de plantas daninhas (Tabela 3). Segundo Rodrigues \& Almeida (2011), estes herbicidas controlam com eficácia um grande número de espécies monocotiledôneas e eudicotiledôneas. Em trabalho conduzido por Fontes et al. (2010) foi constatada redução de mais de $75 \%$ da infestação por plantas daninhas em área cultivada com feijão-caupi após aplicação de oxadiazon, com dose de 600 g i.a. ha $^{-1}$.

Tabela 3. Cobertura da superfície do solo (Cobsolo, \%) por plantas daninhas vivas, massa da parte aérea de plantas daninhas secas $\left(\mathrm{g} \mathrm{m}^{-2}\right)$ monocotiledôneas (Mono), eudicotiledôneas (Dico) e total (Total) e produtividade de grãos $\left(\mathrm{kg} \mathrm{ha}^{-1}\right)$ da variedade de feijão-caupi BRS Guariba.

\begin{tabular}{|c|c|c|c|c|c|c|c|c|}
\hline \multirow{2}{*}{ Tratamentos } & \multirow{2}{*}{\multicolumn{2}{|c|}{$\begin{array}{c}\text { Cobsolo } \\
(\%)\end{array}$}} & \multicolumn{4}{|c|}{ Massa de plantas daninhas secas $\left(\mathrm{g} \mathrm{m}^{-2}\right)$} & \multirow{2}{*}{\multicolumn{2}{|c|}{$\begin{array}{l}\text { Produtividade } \\
\left(\mathrm{kg} \mathrm{ha}^{-1}\right)\end{array}$}} \\
\hline & & & Mono & Dico & Tota & & & \\
\hline Oxadiazon & 4 & $\mathrm{a}$ & 0,3 & 1,1 & 1,4 & $\mathrm{a}$ & 802,6 & $\mathrm{a}$ \\
\hline Sulfentrazone & 8 & a & 0,9 & 1,7 & 2,6 & $a b$ & 785,1 & a \\
\hline Bentazon & 27 & $\mathrm{~b}$ & 5,5 & 2,4 & 7,9 & $\mathrm{c}$ & 759,5 & $\mathrm{a}$ \\
\hline Bentazon+paraquat & 16 & $a b$ & 1,8 & 1,3 & 3,1 & $\mathrm{a}$ & 113,8 & $\mathrm{c}$ \\
\hline Fomesafen & 31 & $\mathrm{~b}$ & 5,4 & 0,7 & 6,1 & $\mathrm{bc}$ & 422,3 & $\mathrm{~b}$ \\
\hline Fluazifop-p-butyl & 15 & $a b$ & 0,2 & 2,1 & 2,3 & $\mathrm{a}$ & 766,4 & $\mathrm{a}$ \\
\hline Fomesafen+fluazifop-p-butyl & 13 & $a b$ & 0,5 & 0,8 & 1,3 & a & 521,6 & $\mathrm{~b}$ \\
\hline Testemunha capinada & 2 & a & 1,1 & 0,2 & 1,3 & a & 843,0 & $\mathrm{a}$ \\
\hline Testemunha sem capina & 92 & $\mathrm{c}$ & 14,5 & 6,7 & 21,2 & $\mathrm{~d}$ & 359,5 & $\mathrm{~b}$ \\
\hline Coeficiente de variacão (\%) & 24,3 & & - & - & 25,3 & & 12,63 & \\
\hline
\end{tabular}


As maiores cobertura da superfície do solo e massa seca de plantas daninhas foram registradas nos tratamentos sem controle de plantas daninhas, assim como nos constituídos por herbicidas que controlam espécies eudicotiledôneas, como bentazon e fomesafen. $\mathrm{Na}$ Tabela 1, verifica-se que entre as espécies daninhas mais importantes por ocasião do preparo do solo estavam presentes monocotiledôneas (Commelina erecta e Paspalum virgatum), tolerantes aos herbicidas que controlam espécies eudicotiledôneas, o que contribuiu para este resultado. Além disso, algumas espécies eudicotiledôneas não são controladas com aplicações de bentazon. Machado et al. (2006) relataram que a mistura de fluazifop-p-butyl + bentazon $(125+480 \mathrm{~g}$ i.a. ha $^{-1}$ ) não foi eficaz no controle de Coronopus didymus, Galinsoga parviflora, Amaranthus sp., Euphorbia heterophylla, Lepidium virginicum e Solanum americanum, todas eudicotiledôneas. No trabalho foram identificadas na área experimental as espécies E. heterophylla e A. retroflexus, tolerantes ao bentazon. Ruas et al. (2005), constataram que o fomesafen não foi eficaz no controle de $E$. heterophylla..

A produtividade de grãos foi afetada pela aplicação dos herbicidas bentazon + paraquat, fomesafen e fomesafen + fluazifop-pbutyl, sendo que a menor produtividade foi verificada para mistura bentazon + paraquat em pós-emergência (Tabela 3). Além de a fitotoxicidade ter sido elevada (Tabela 2), a mistura de bentazon + paraquat provocou morte de plantas e, consequente redução da população, resultando em elevada queda de produtividade, sendo $86 \%$ menor que a testemunha com capinas.

A ação do fomesafen condicionou intensa redução de área foliar devido à queda de folhas, causando redução de produtividade do feijão-caupi em aproximadamente $38 \%$ quando comparada à testemunha capinada, evidenciando pouca tolerância da variedade BRS Guariba a este herbicida. Ibrahim et al.
(2010) e Mondal et al. (2011) relataram que a desfolha de plantas de feijão-caupi e feijãomungo-verde, respectivamente, afetou negativamente a formação de ramos, flores e vagens. Alem disso, às injúrias provocadas pelo fomesafen (perda de folhas e o atraso para atingir a fase reprodutiva), como apresentadas na Tabela 2, associado à redução do volume de chuvas nas fases de floração e enchimento de grãos (Figura 1), pode ter depreciado ainda mais os níveis de produtividade.

As produtividades de grãos obtidas nos tratamentos com aplicação do bentazon e do fluazifop-p-buyl foram semelhantes à da testemunha capinada, evidenciando mais uma vez, além da ausência de sintomas visuais de intoxicação (Tabela 2), a seletividade destes herbicidas para as plantas da cultura. Fontes et al. (2001) também avaliaram a seletividade dos herbicidas bentazon e fluazifop-p-butyl para o feijão-mungo-verde, e os mesmos foram seletivos a esta cultura do gênero Vigna.

A interferência de plantas daninhas durante todo o ciclo da cultura resultou em redução da produtividade em cerca de $42 \%$.

\section{Conclusões}

A variedade de feijão-caupi BRS Guariba apresentou tolerância diferenciada aos herbicidas aplicados em pré e pós-emergência da cultura. A associação simultânea de bentazon + paraquat não deve ser aplicada na cultura do feijão-caupi em razão dos efeitos prejudiciais verificados nas plantas. As aplicações em pré-emergência de oxadiazon e sulfentrazone, assim como de bentazon e fluazifop-p-butyl em pós-emergência garantiu de bom a excelente controle de plantas daninhas, resultando em produtividades semelhantes ao controle realizado por meio de capinas aos 20 e 35 DAE. A aplicação de fomesafen isoladamente ou associado ao fluazifop-p-butyl em pós-emergência, embora tenha apresentado bom controle das plantas daninhas, provocou fitointoxicação com influência negativa na produtividade. 


\section{Referências}

ASSUNÇÃO, I.P. et al. Diversidade genética de Begomovirus que infestam plantas invasoras na região Nordeste. Planta Daninha, v.24, n.2, p.239-244, 2006.

BEZERRA, A.A.C. et al. Comportamento morfoagronômico de feijão-caupi, cv. BRS Guariba, sob diferentes densidades de plantas. Revista de Ciências Agrárias, v.55, n.3, p.184-189, 2012.

BRAUN-BLANQUET, J. Fitosociologia bases para el studio de las comunidades vegetales. 1. ed. Rosário: H. Blume Ediciones, 1979. $820 \mathrm{p}$.

EMPRESA BRASILEIRA DE PESQUISA AGROPECUÁRIA - EMBRAPA. Embrapa Solos. Sistema brasileiro de classificação de solos. 3 ed. Rio de Janeiro, 2013. 353 p.

FADAYOMI, O.; OLOFINTOYE, J.A. Weed control in cowpea (Vigna unguiculata) (L) Walp) with imidazolinone herbicide mixtures. Journal of Agriculture Research and Development, v.4, n.2, p.104-121, 2005.

FONTES, J.R.A. et al. Efeitos de herbicidas no controle de plantas daninhas na cultura do feijão-mungo-verde [Vigna radiata (L.) Wilczek. Ciência e Agrotecnologia, v.25, n.2, p.1087-1096, 2001.

FONTES, J.R.A. et al. Metolachlor e fomesafen aplicados via irrigação por aspersão em plantio direto e convencional. Planta Daninha, v.24, n.1, p.99-106, 2006.

FONTES, J.R.A.; GONÇALVES, J.R.P.; MORAIS, R.R. Tolerância do feijão-caupi ao herbicida oxadiazon. Pesquisa Agropecuária Tropical, v.40, n.1, p.110-115, 2010.

FRANS, R.E.; TALBERT. R.E. Design of field experiments and the measurement and analysis of plant responses. In: TRUELOVE, B. Research Methods in Weed Science. Auburn:
Southern Weed Science Society, 1977. p.1523.

FREITAS, F.C.L. et al. Interferência de plantas daninhas na cultura do feijão-caupi. Planta Daninha, v.27, n.2, p.241-247, 2009.

HARRISON Jr., H.F.; FERY, R.L. Differential bentazon response in cowpea (Vigna unguiculata). Weed Technology, v.7, n.3, p.756-758, 1993.

IBRAHIM, U.; AUWALU, B.M.; UDOM, G.N. Effect of stage and intensity of defoliation on the performance of vegetable cowpea (Vigna unguiculata) (L.) Walp). World Journal of Agricultural Sciences, v.6, n.4, p.460-465, 2010.

ISHAYA, V.B.; TUNKU, P.; YAHAYA, M.S. Effect of pre-emergence herbicide mixtures on cowpea (Vigna unguiculata (L.) Walp) at Samaru, in Northern Nigeria. Crop Protection, v.27, n.7, p.1105-1109, 2008.

MACHADO, A.F.L. et al. Misturas de herbicidas no manejo de plantas daninhas na cultura do feijão. Planta Daninha, v.24, n.1, p.107-114, 2006.

MONDAL, M.M.A. et al. Effect of defoliation on growth, reproductive characters and yield in mungbean [Vigna radiata (L.) Wilczek]. Australian Journal of Crop Science, v.5, n.8, p.987-992, 2011.

MUELLER-DOMBOIS, D.; ELLEMBERG, H. Aims and methods of vegetation ecology. New York: John Willey \& Sons, 1974. 547 p.

ROCHA, M.M. et al. Adaptabilidade e estabilidade produtiva de genótipos de feijãocaupi de porte semi-ereto na região Nordeste do Brasil. Pesquisa Agropecuária Brasileira, v.42, n.9, p.1283-1289, 2007.

RODRIGUES, B.N.; ALMEIDA, F.S. Guia de herbicidas. 6 ed. Londrina: Edição dos autores, 2011. 697p.

RUAS, R.A.A. et al. Aplicação do fomesafen via irrigação por aspersão no controle de 
Euphorbia heterophylla. Planta Daninha, v.23, n.3, p.501-507, 2005.

SAEG. Saeg: sistema para análises estatísticas, versão 9.1. Viçosa: UFV, 2007.

SILVA, C.M.; FERREIRA, L.R.; VIEIRA, R.F. Tolerância do feijão caupi (Vigna unguiculata var. USA) a herbicidas aplicados em pré e pós-emergência. Boletim Informativo, v.6, n.1, p.6-7, 2000.

SILVA, J.B.F. et al. Controle de plantas daninhas em feijão-de-corda em sistema de semeadura direta. Planta Daninha, v.21, n.1, p.151-157, 2003.

VIDAL, R.A. Herbicidas: mecanismos de ação e resistência de plantas. Porto Alegre: Edição do autor, 1997. 165p.

ZILLI, J.E. et al. Resposta do feijão-caupi à inoculação com estirpes de Bradyrhizobium recomendadas para a soja. Revista Brasileira de Ciência do Solo, v.35, n.3, p.739-742, 2011. 